\title{
Darkness and the dawn?
}

\author{
Joseph L. Graves Jr. ${ }^{1,2^{*}}$
}

\section{Book details}

Evolution Challenges: Integrating Research and Practice in Teaching and Learning about Evolution, edited by Karl S. Rosengren, Sarah Brem, E. Margaret Evans, and Gale Sinatra, (New York, NY: Oxford University Press), 2012.

For evolutionary scientists, the darkness is that while the rest of the industrialized modern world displays strong acceptance of organic evolution ( $80 \%$ adults in Northern Europe and Japan); only about $40 \%$ of adults in the United States report acceptance of evolution. Gallup polls of public acceptance of evolution in the United States indicate that this situation has persisted for the latter half of the twentieth century. Indeed, we see evidence of some back pedaling with regard to evolutionary science in American society, creationist museums in Kentucky, attacks on state standards including evolution across the Midwest and the South East, and calls for opting out of evolution lessons for students with strong objections to evolutionary reasoning. Despite all these troubling developments, it may yet be possible to see the dawn. Evolution Challenges is an attempt to apply an interdisciplinary approach to addressing why Americans continue to resist evolutionary reasoning. This book resulted from discussions and meetings generated by a National Science Foundation grant to Sarah Brem, E. Margaret Evans, and Gale Sinatra (three of the four editors). The contributors to the book include some of the foremost researchers and practitioners in the fields of children's cognitive development, evolution teaching, and assessment of formal and informal instruction of evolutionary science concepts. This list includes several individuals that I know personally and have had the opportunity to observe both their advanced thinking on these issues and their deep commitment to evolution education. The editors argue that the most unique contribution of this volume is the combination of researchers who study basic aspects of

\footnotetext{
*Correspondence: gravesjl@ncat.edu

2 Joint School of Nanoscience and Nanoengineering, North Carolina A\&T

State University \& UNC Greensboro, Greensboro 27401, NC, USA

Full list of author information is available at the end of the article
}

cognitive development, evolution educators, and those who are designing new methods of teaching evolution (on-line and in museums). After a careful read, I am in agreement that this approach is much needed and long overdue.

The book is divided into two sections. The first section (chapters 1-9) focuses on factors that influence the acquisition of evolution understanding (as well as acceptance). These are clearly not the same thing, as students can understand the principles of organic evolution, yet reject their implications. The chapters evaluate some of the major constraints to understanding/acceptance of evolution in a multi-factorial way. Thus while most evolutionary scientists/educators are familiar with some of these issues as single variables (religiosity, prior misconceptions, social-cultural contexts) rarely are these considered in combination. The contributors recognize that these constraints also operate at three levels, the individual, the task, and the environment. At the individual level they were concerned with the characteristics of the individual (age, psychology, prior misconceptions), at the task (particular concepts or representations that play a role in learning evolution, e.g. tree thinking, progressive evolution icon), and the environment (no individual learns in isolation, so learning is influenced within the frame work of the socio-political situation experienced by individuals). It is precisely in the last level of the constraint that the book shows its greatest weakness. There is absolutely no consideration within its pages of the fact that different ethnic sub-populations in the United States differ in their acceptance to evolution, and how the analysis presented with this section might apply to this issue. For example, Matuk and Uttal's chapter six is entitled "Narrative Spaces in the Representation and Understanding of Evolution." One of the narratives they discuss is the folk evolution iconic progression towards humans 
and how this cast in language that implies goal-direction and intentionality. They do not discuss the idea that this icon might have particularly negative effects on African American student acceptance of evolution due to its association with the African as ape association displayed by many Europeans (Eberhardt 2005). Unfortunately, this lack of interest in/analysis of ethnic sub-population understanding and acceptance of evolution are common amongst those who study evolution acceptance/understanding (Bailey et al. 2011). This is also indicated by the fact that the volume's authors did not include anyone who was either an underrepresented minority, or has a track record or interest in minority student representation in evolutionary science.

The second portion of the book focuses on bringing together multiple levels of analysis to bear on evolution teaching and learning. These chapters unite cognitive, affective, curricular, and historical issues to develop a comprehensive approach to the issues underlying the difficulties in teaching and learning evolution. This is undoubtedly the strongest aspect of this collection. Evolutionary scientists naively opine the lack of public acceptance and understanding evolution precisely because they have not attempted this integration. Personally I have never been surprised by the reluctance of a society whose existence relies on the ignorance and complacency of its citizens to widely accept the critical habits of mind necessary for understanding and acceptance of evolutionary science. Not as cynical as I, these authors outline a program by which we might advance a critical evolution science agenda in the United States. One suggestion which may not be widely accepted by evolutionary scientists is the idea of presenting evolution as it is best learned; which is different from presenting a comprehensive evolution curriculum. This idea relies on the relative lack of rejection of microevolutionary concepts, compared to the epistemological and ideological roadblocks that arise when macroevolutionary concepts are introduced. What is clear from the analysis presented in this section that it is unlikely that we will be able to effectively teach evolutionary science by ignoring the religiosity of the lay-public.

One of the most important contributions in section two is that of Chinn and Buckland (chapter 10). This work validates something that many of us have always thought about education. That is, it is more important to alter how students think, than what they think. Of course, with regards to evolutionary science, if you achieve the former, you will definitely achieve the latter. This chapter revolves around their model, Promoting Reasoning and Conceptual Change in Science (PRACCIS). This focuses on advancing the way students think about evidence and ultimately scientific knowledge. Finally, the book ends with some chapters focused on specific curricula. The general issues that emerged across these chapters were setting goals for curricula that are achievable and tractable, and also about whether it is better to teach less, but in the process achieve more learning. The models presented include the use of museum exhibits (Diamond and Kociolek, chapter 16; Diamond et al. chapter 17), websites (Understanding Evolution, Thanukos and Scotchmoor, chapter 18) preservice teacher courses (Southerland and Nadelson, chapter 15), and undergraduate courses (Nelson, chapter 14).

In summary, Evolution Challenges addressed much needed discussion of how we can both understand the resistance to evolution understanding and acceptance and proposes a series of well-reasoned approaches to redress these. It is an interdisciplinary approach authored by leading researchers in the fields of cognitive development and evolution education. It is an essential read for anyone interested in improving the environment for evolution education in the United States.

\section{Author details}

${ }^{1}$ American Association for the Advancement of Science, Section G: Biological Sciences, Washington DC 20005, USA. ${ }^{2}$ Joint School of Nanoscience and Nanoengineering, North Carolina A\&T State University \& UNC Greensboro, Greensboro 27401, NC, USA.

Received: 1 September 2015 Accepted: 22 September 2015

Published online: 12 October 2015

References

1. Bailey G, Han J, Wright D, Graves JL. Religiously expressed fatalism and the perceived need for science and scientific process to empower agency. Int J Sci Soc. 2011;2(3):55-88.

2. Eberhardt J. Imaging Race. Am Psychol. 2005;60(2):181-90.
Submit your manuscript to a SpringerOpen ${ }^{\circ}$ journal and benefit from:

- Convenient online submission

- Rigorous peer review

- Immediate publication on acceptance

- Open access: articles freely available online

- High visibility within the field

Retaining the copyright to your article

Submit your next manuscript at $>$ springeropen.com 